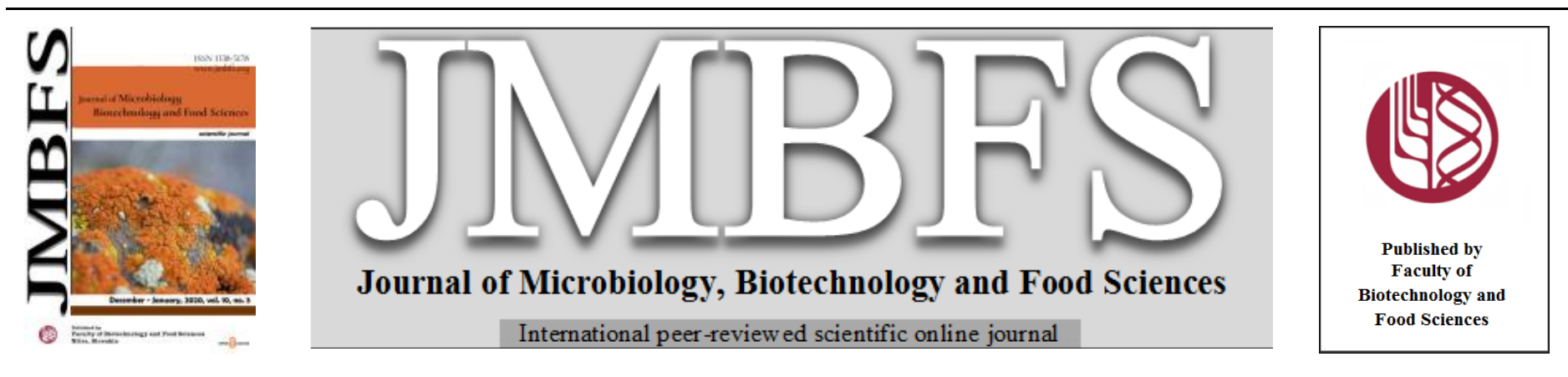

\title{
MONTE CARLO ANALYSIS FOR MICROBIAL GROWTH CURVES
}

\author{
Hasan Basri Öksüz ${ }^{1}$, Sencer Buzrul $*^{2}$ \\ $\operatorname{Address}(e s):$ \\ ${ }^{1}$ Department of Electrical and Electronics Engineering, Faculty of Engineering and Architecture, Konya Food and Agriculture University, Konya, Turkey. \\ ${ }^{2}$ Department of Food Engineering, Faculty of Engineering and Architecture, Konya Food and Agriculture University, Konya, Turkey.
}

*Corresponding author: sencer.buzrul@gmail.com

doi: 10.15414/jmbfs.2020.10.3.418-423

ARTICLE INFO

Received 15. 3. 2020

Revised 11. 8. 2020

Accepted 22. 9. 2020

Published 1. 12. 2020

Regular article

OPEN $\partial_{\text {ACCESS }}$

\begin{abstract}
Three most commonly used primary models (Gompertz, Baranyi and three-phase linear models) to describe the microbial growth curves were applied to three different isothermal growth data of Listeria monocytogenes. Further Monte Carlo analysis was performed with 100, 1000 and 10000 simulations. The results indicated that there was no reason to use higher number of simulations since the simulations produced almost identical means of the model parameter values for all models. Moreover, the models had similar coefficient of variation values for the initial $\left(\log _{10} N_{0}\right)$ and maximum $\left(\log _{10} N_{\max }\right)$ number of bacteria. On the other hand, the Gompertz model had the highest coefficient of variation for the growth rate $\left(\mu_{\max }\right)$ and the Baranyi model had the highest coefficient of variation for the lag time ( $\lambda$. Correlations between the parameters $\log _{10} N_{0}$ and $\lambda$, and $\mu_{\max }$ and $\lambda$ could be easily observed after the Monte Carlo analysis for all models. Deviation from normal distribution for the parameter $\lambda$ for the three-phase linear model was evident, other than that all parameters for all models had normal distribution. It was concluded that Monte Carlo analysis can be used as a simple yet an effective method to describe the uncertainty in model parameters and correlation between the parameters as well as the spread of the possible parameter values.
\end{abstract}

Keywords: Predictive microbiology; Monte Carlo simulation; uncertainty; variability; curve fit

\section{INTRODUCTION}

Mathematical models have been used to evaluate microbial behavior such as inactivation, survival or growth under different environmental conditions (Gwak et al., 2015). The growth of a homogenous microbial population in a closed habitat can be described by a sigmoidal curve with three phases: lag, exponential and death (Lebert and Lebert, 2006). Growth of microorganisms can be described by several models and one can find many state of the art reviews on the primary growth models (McKellar and Lu, 2004; Peleg and Corradini, 2011). Growth models such as Baranyi and Gompertz models are deterministic viz., models always give the same output when provided with the same input (no uncertainty) (Heldman and Newsome, 2003). However, biological variability in strains of a bacterial specie and in model parameters, and experimental uncertainty play an important role. Hence, stochastic modeling i.e., a model that gives a variable output when provided with the same input (variability is a part of the model) (Heldman and Newsome, 2003) should be investigated more deeply. Monte Carlo (MC) analysis is based on random computer simulations of the experimental data which are described by a mathematical model. It is most probably the simplest and the best analysis to describe the uncertainty in model parameters (van Boekel, 2009). The usage of MC in the field of predictive microbiology can be found in literature (Abe et al., 2019; Cassin et al., 1998; Coleman and Marks, 1999; Koyama et al., 2019; Nauta, 2000; Nicolaï and Van Impe, 1996). Furthermore, it was also used for primary growth models such as Baranyi model (Poschet $\boldsymbol{e t}$ al., 2004; 2003) and Gompertz model (Lambert $\boldsymbol{e t}$ al., 2012).

The main objective of this study was to investigate MC analysis for most commonly used isothermal microbial growth models, namely the Gompertz, the Baranyi and the three-phase linear models with three different published isothermal growth data sets of Listeria monocytogenes. Further objective was to make comparisons between the models based on the results of MC simulations such as correlations of the model parameters.

\section{MATERIALS AND METHODS}

\section{Data sets}

Growth data of Listeria monocytogenes in three different studies were used as the data bases for this study. Lambert $\boldsymbol{e t}$ al. (2012) listed the growth data of $L$. monocytogenes at $30{ }^{\circ} \mathrm{C}$ in Tryptic Soy Broth containing 9\% salt. Alavi et al. (1999) showed the growth data of L. monocytogenes Scott A at $4{ }^{\circ} \mathrm{C}$ in sterilized whole milk with a figure. Data given in the figure of Alavi et al. (1999) were digitized using WinDIG 2.5 (Lovy, 2002). McKellar (1997) also showed the growth data of L. monocytogenes Scott A at $5{ }^{\circ} \mathrm{C}$ Tryptic Soy Broth supplemented with $0.6 \%$ yeast extract with a figure. The data in the figure of McKellar (1997) were tabulated by McKellar and Lu (2004). All data were organized in a Microsoft ${ }^{\circledR}$ Excel (Microsoft Corporation, Redmond, WA, USA) spreadsheet before to use.

\section{Mathematical models}

\section{Modified Gompertz model}

The British mathematician Benjamin Gompertz introduced a formula to describe the mortality of humans in 1825 (Gompertz, 1825). A century later it was applied as a growth model [Eq.(1)] (Winsor, 1932) and although it was more popular at the beginning of 1990s, today it is still a commonly used model to describe microbial growth data (Peleg and Corradini, 2011). Zwietering $\boldsymbol{e t}$ al. (1990) reparametrized the original Gompertz equation in order to obtain interpretable parameters. This modified version of the Gompertz model was used in the present study and for simplicity we used the term "Gompertz model" not the modified Gompertz model: 
$\log _{10} N(t)=$

$\log _{10} N_{0}+\left(\log _{10} N_{\max }-\log _{10} N_{0}\right) \cdot \exp \left\{-\exp \left[\frac{\mu_{\max } \cdot e}{\left(\log _{10} N_{\max }-\log _{10} N_{0}\right)} \cdot(\lambda-t)+\right.\right.$

1]\} (1)

where $\log _{10} N_{0}$ is the initial number of bacteria while $\log _{10} N_{\max }$ is the maximum number of bacteria reached during the growth. The maximum growth rate and lag time are denoted by $\mu_{\max }$ and $\lambda$, respectively.

\section{Baranyi model}

Baranyi and Roberts (1994) proposed a microbial growth model, which is perhaps the most commonly used microbial growth model today:

$\frac{d N(t)}{d t}=\frac{q(t)}{1+q(t)} \cdot \mu_{\max }^{\prime} \cdot N(t) \cdot\left\{1-\left[\frac{N(t)}{N_{\max }}\right]^{m}\right\}$

and

$\frac{d q(t)}{d t}=\mu_{\max }^{\prime} \cdot q(t)$

where $q(t)$ represents the concentration of a critical substance for bacterial growth, and the term $q(t) /[1+q(t)]$ in Eq.(2) represents the physiological state of the cells and also associated with the with the lag time $(\lambda)$ through the introduced parameter $h_{0}=\mu_{\max }^{\prime} \cdot \lambda$ which appears in the solution of the rate equation (Peleg and Corradini, 2011). The curvature parameter, $m$, is generally set to 1 for simplicity. Note that $\mu_{\max }^{\prime}$ is the maximum specific growth rate.

For static environmental conditions such as the constant temperature the following analytical solution could be obtained (Poschet et al., 2005):

$N(t)=\frac{N_{\max } \cdot N_{0} \cdot\left[\frac{1+q_{0} \cdot \exp \left(\mu_{\max }^{\prime} \cdot t\right)}{1+q_{0}}\right]}{N_{\max }-N_{0}+N_{0} \cdot\left[\frac{1+q_{0} \cdot \exp \left(\mu_{\max }^{\prime} t\right)}{1+q_{0}}\right]}$

It is known that $q(t=0)=q_{0}=\frac{1}{\exp \left(h_{0}\right)-1}($ Jaloustre et al., 2011; Manthou $\boldsymbol{e t}$ al., 2019) and in order to compare the growth rates of Baranyi and Gompertz models we made the modification $\mu_{\max }^{\prime}=\ln 10 \cdot \mu_{\max }$ in the equation where $\mu_{\max }$ is the maximum growth rate. Therefore, in the end we used the following equation to obtain the parameters of the Baranyi equation:

$\log _{10} N(t)=$

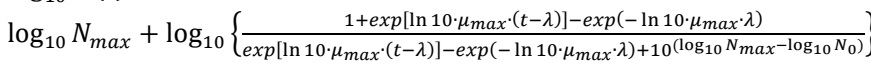

(5)

\section{Three phase linear model}

Buchanan et al. (1997) introduced a simple model to describe isothermal growth curves:

$$
\begin{gathered}
\text { If } t \leq \lambda \log _{10} N(t)=\log _{10} N_{0} \\
\text { If } \lambda<t<t_{\text {max }} \log _{10} N(t)=\log _{10} N_{0}+\mu \cdot(t-\lambda) \\
\text { If } t \geq t_{\text {max }} \log _{10} N(t)=\log _{10} N_{0}+\mu \cdot\left(t_{\text {max }}-\lambda\right)
\end{gathered}
$$

Note that $\log _{10} N_{\max }$ can be calculated as $\log _{10} N_{0}+\mu \cdot\left(t_{\max }-\lambda\right)$ where $t_{\max }$ is the time at which maximum population $\left(\log _{10} N_{\max }\right)$ is reached. Moreover, since the slope of the exponential phase is constant i.e., exponential phase is described by a linear line, $\mu$ was used instead of $\mu_{\max }$ contrary to Gompertz and Baranyi models.

\section{Monte Carlo analysis}

To perform MC analysis or simulation two information are necessary: (i) adequate mathematical model or models; (ii) uncertainty or standard deviation in the experimental data (van Boekel, 2009). Since the aforementioned models were used to describe the growth data of $L$. monocytogenes, only experimental uncertainty should be determined. For the plate count data experimental error is in the order of $1 \log _{10}$ unit (Jarvis, 1989; Mossel et al., 1995) therefore, datum point $\pm 0.5 \log _{10}$ unit was used for MC simulation (Poschet et al., 2003) for the data of Lambert et al. (2012) and Alavi et al. (1999). For the data of McKellar (1997) datum point $\pm 0.35 \log _{10}$ unit was used because generated data with \pm 0.5 $\log _{10}$ unit made the models inappropriate (several negative lag times were obtained for each number of simulations) - data not shown. $\mathrm{MC}$ analysis were performed as follows:

1. Models were fitted to each data set and parameters $\left(\log _{10} N_{0}, \log _{10} N_{\max }\right.$ $\mu_{\max }$ and $\lambda$ ) were estimated as usually.

2. By using the models and their estimated parameters, perfect data were obtained.

3. Data were randomly generated on the perfect data with $\pm 0.5 \log _{10}$ unit [ $\pm .35 \log _{10}$ unit for the data of McKellar (1997)]. Since many generations should be repeated depending on the problem, we ran the simulations for 100,1000 and 10000 times in order to make comparisons between the simulations and the models.

4. Generated data sets were fitted with the suitable model one by one and the parameters were tabulated.

5. Tabulated parameters were transformed into histograms and correlation plots between the parameters were sketched for 100,1000 and 10000 simulations separately.

MATLAB version 9.3 (The MathWorks, Inc., Natick) was used for data generation and model fitting, and SigmaPlot version 12.00 (Chicago, IL, USA) was used for plotting the graphs.

\section{RESULTS AND DISCUSSION}

\section{Comparison of the models}

Three models, namely the Gompertz [Eq.(1)], the Baranyi [Eq. (5)] and the threephase linear [Eq.(6)] models were fitted to each data set and parameters were estimated by non-linear regression. Fig. 1 shows the fit of the models for the data set of Lambert $\boldsymbol{e t}$ al. (2012) and parameter estimates are given in Table 1. Adjusted coefficient of determination ( $\mathrm{R}^{2}$ adj) and root mean square error (RMSE) values were used to determine the goodness-of-fit of the models. Although the difference between the Gompertz model and the Baranyi model was very small, the Gompertz model was the best model since it had the highest $R^{2}$ adj and lowest RMSE values (Table 1). Based on $\mathrm{R}_{\text {adj }}^{2}$ the Baranyi and the three phase linear models had both the best and identical goodness-of-fits for the data set of Alavi et al. (1999); however, based on RIMSE, which is the most informative indices of goodness-of-fit according to Ratkonsky (2004) the Baranyi model was superior. The Gompertz model had the worst goodness-of-fit for the data set of Alavi et al. (1999) - see Table S1. For the data set of McKellar (1997) the Baranyi model was again the best model followed by the Gompertz and the three phase linear models (Table S2).

\begin{tabular}{|c|c|c|c|c|c|c|c|}
\hline & $\log _{10} N_{0}$ & $\log _{10} N_{\max }$ & $\mu_{\max } / \mu$ & $\lambda$ & $\mathbf{t}_{\max }$ & $\mathbf{R}_{\text {adj }}^{2}$ & RMSE \\
\hline Gompertz & $3.9506 \pm 0.0279$ & $8.8493 \pm 0.0362$ & $0.1714 \pm 0.0050$ & $19.8242 \pm 0.4993$ & - & 0.9982 & 0.0908 \\
\hline Baranyi & $3.9139 \pm 0.0303$ & $8.7399 \pm 0.0307$ & $0.1441 \pm 0.0035$ & $17.8966 \pm 0.5625$ & - & 0.9981 & 0.0923 \\
\hline Three phase linear & $3.9583 \pm 0.0279$ & $8.7511^{a}$ & $0.1311 \pm 0.0028$ & $16.6997 \pm 0.5106$ & $53.2579 \pm 0.5278$ & 0.9975 & 0.1072 \\
\hline
\end{tabular}

Table 1 Parameters of growth models \pm standard errors and goodness-of-fit of the models for the growth data of Listeria monocytogenes at $30{ }^{\circ} \mathrm{C}$ in Tryptic Soya Broth containing 9\% salt. Original data are from Lambert et al. (2012).

${ }^{a}$ Calculated from $\log _{10} \mathrm{~N}_{0}+\mu \cdot\left(\mathrm{t}_{\max }-\lambda\right)$ 
(a)

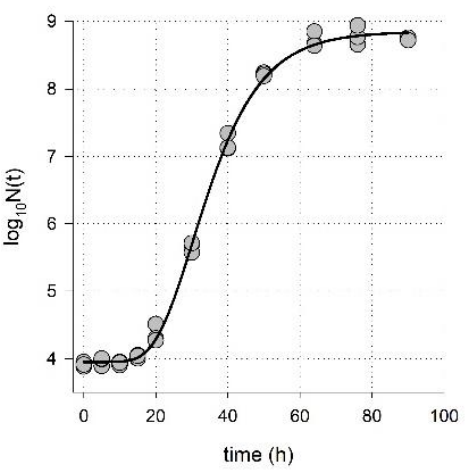

(b)

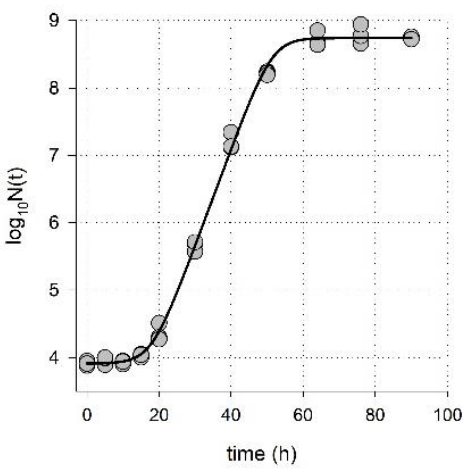

(c)

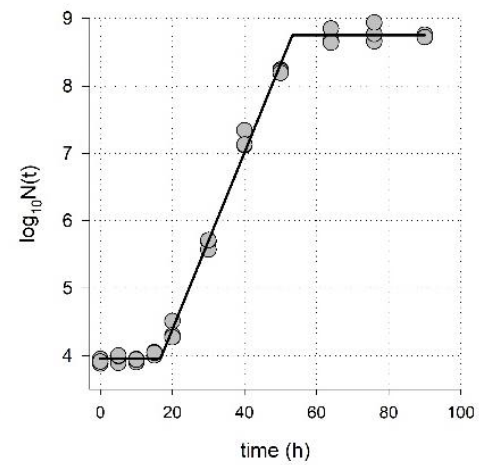

Figure 1 Growth data (gray circles) of Listeria monocytogenes at $30{ }^{\circ} \mathrm{C}$ in Tryptic Soya broth containing $9 \%$ salt. Data were fitted with the Gompertz model (a); the Baranyi model (b) and three phase linear model (c). Original data are from Lambert et al. (2012).

Similar initial number of bacteria $\left(\log _{10} N_{0}\right)$ was obtained for all models whereas the Gompertz model gave the highest maximum number of bacteria $\left(\log _{10} N_{\max }\right)$. On the other hand, the Baranyi and the three phase linear models had almost identical $\log _{10} N_{\max }$ values (Table 1). The Gompertz model produced the highest maximum growth rate $\left(\mu_{\max }\right)$ and lag time $(\lambda)$ values while the three phase linear model had the lowest and the Baranyi model was in between being closer to the three phase linear model (Table 1). This discussion was also valid for the other data sets (Alavi et al., 1999; McKellar, 1997) where the model fits and parameter estimates are given in Figs. S1 and S2, and Table S1 and S2, respectively.

The Gompertz model has a specific curvature around the inflection point of the "S" shaped curve (Baranyi et al., 1993) and therefore it was not surprising that it produced highest $\mu_{\max }$ and $\lambda$ values. Lag time calculation with the Gompertz model could give wrong outcomes since growth may occur before the estimated $\lambda$. Many researchers pointed out the limitations of the Gompertz equation, especially the overestimation of $\mu_{\max }$ and $\lambda$ (Dalgaard, 1995; McKellar and Knight, 2000; Membré et al., 1999; Whiting and Cygnarowicz-Provost, 1992). Moreover, unlike the Baranyi and the three phase linear models the Gompertz model did not reach to a plateau (Figs. 1, S1 and S2) that is why $\log _{10} N_{\max }$ was also highest for the Gompertz model (Tables 1, S1 and S2).

\section{Monte Carlo analysis for the growth models}

A step by step explanation of MC analysis for the data of Lambert et al. (2012) is shown in Fig. 2. Note that three replications were performed at each time value by Lambert et $\boldsymbol{a l}$. (2012) hence three data were generated randomly for each point. On the other hand, since one datum point at each time value were given by Alavi et al. (1999) and McKellar (1997) only one datum was generated for each point - see Figs. S3 and S4.
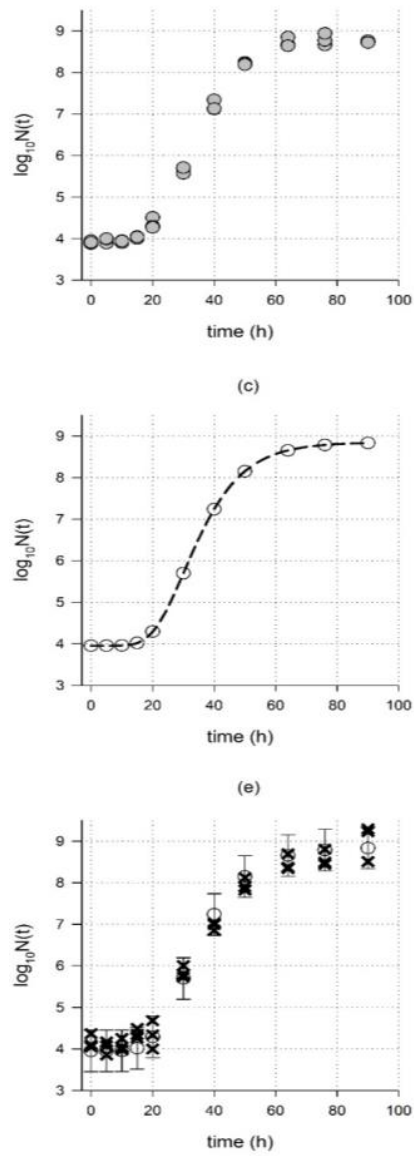
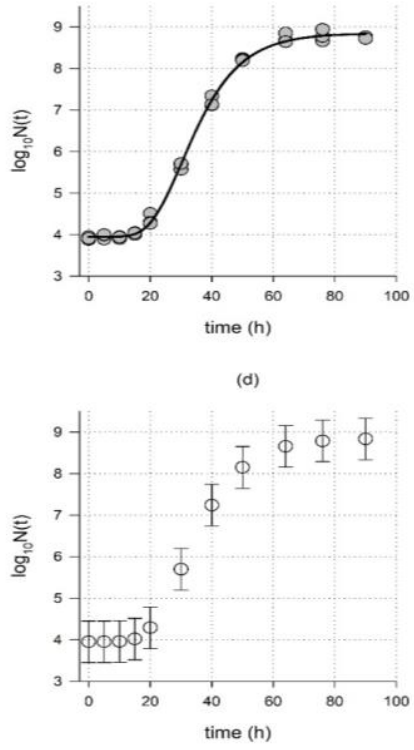

(f)

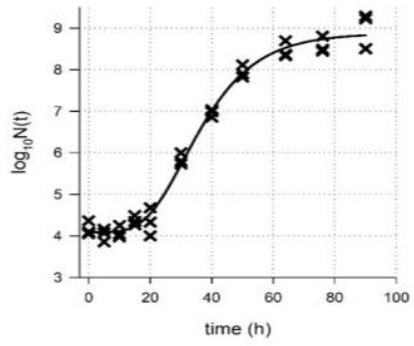

Figure 2 Monte Carlo analysis steps [Adapted from Poschet et al. (2003)] Original growth data (gray circles) of Listeria monocytogenes from Lambert et al. (2012) (a); Fit of the Gompertz model (solid line) to the data (b); Perfect data (white circles) from the fit of the Gompertz model (dashed line) (c); Perfect data (white circles) with $\pm 0.5 \log _{10}$ unit error (error bars) added (d); Randomly generated data (crosses) within $\pm 0.5 \log _{10}$ unit error (e); Fit of the Gompertz model (solid line) to the randomly generated data.

Results of MC analysis for the data of Lambert $\boldsymbol{e t}$ al. (2012) is given in Table 2 There was no significant difference ( $p>0.05$ ) between 100, 1000 and 10000 simulations in terms of parameters' means for all the models tested which could be also said for the other two data sets (Tables S3 and S4). This result indicated that there was no reason to use high number of simulations: 100 simulations was enough for microbial growth data. Garre et al. (2019) also stated that increasing number of iterations performed by $\mathrm{R}$ code i.e., using more than 100 simulations 
had no impact on the results for microbial inactivation. Lambert et al. (2012) used the Gompertz model [the one proposed by (Gibson $\boldsymbol{e t}$ al., 1987)] and showed that parameter estimates (means) of 100 simulations with Excel and 10000 simulations with Mathematica were almost identical. Our finding with same data set but with different growth models applied were similar to those of Lambert et al. (2012). Moreover, results of two more data sets did support this judgement. The results of Lambert et al. (2012) and the present study also brought out that Excel which is easy to access, could be safely use to generate 100 simulations randomly plus SOLVER Add-In package of Excel could be used to fit the non-linear models to the generated data Lambert $\boldsymbol{e t}$ al. (2012). Note that SOLVER in Excel could not produce parameter estimates with their uncertainties, that is to say standard errors or confidence intervals of the parameters could not be obtained. However, MC simulation can be used together with the SOLVER tool in Excel to obtain confidence intervals (Lambert et al.,
2012). Also note that the Bayesian approach may also be used instead of the procedure presented here. However, the aim here was to show the MC method. Moreover, Bayesian procedure requires learning and applying of a programming language like R or Phyton (van Boekel, 2020)

Poschet et al. (2003) performed MC analysis 5 times (for the growth data of $L$. innocua and Escherichia coli fitted with the Baranyi model) for different number of iterations and observed that 10000 iterations, compared to 100 and 1000 , produce more stable mean values of parameters and standard deviations i.e., less variation on the mean value of the parameters of the Baranyi model is seen (Poschet et al., 2003). Nevertheless, the gap between the mean values of the parameters obtained from 100, 1000 or 10000 iterations were low.

Table 2 Results of Monte Carlo simulation (100, 1000 and 10000 iterations) for the growth data of Listeria monocytogenes at $30{ }^{\circ} \mathrm{C}$ in Tryptic Soya Broth containing 9 $\%$ salt. Original data are from Lambert et al. (2012).

\begin{tabular}{|c|c|c|c|c|c|c|c|c|c|c|c|c|c|}
\hline \multicolumn{2}{|l|}{ Models } & \multicolumn{4}{|c|}{$\mathrm{n}_{\mathrm{MC}}=100$} & \multicolumn{4}{|c|}{$n_{M C}=1000$} & \multicolumn{4}{|c|}{$\mathrm{n}_{\mathrm{MC}}=10000$} \\
\hline \multirow{5}{*}{$\begin{array}{l}\text { :े } \\
\text { : } \\
\text { : }\end{array}$} & & mean & SD & $\max$ & $\min$ & mean & SD & $\max$ & $\min$ & mean & SD & $\max$ & $\min$ \\
\hline & $\log _{10} \mathrm{~N}_{\text {max }}$ & 8.8528 & 0.1098 & 9.1550 & 8.5892 & 8.8502 & 0.1097 & 9.1742 & 8.5196 & 8.8530 & 0.1178 & 9.2614 & 8.0650 \\
\hline & $\lambda$ & 19.7194 & 1.7137 & 23.3838 & 15.4943 & 19.8599 & 1.6202 & 24.3135 & 14.5430 & 19.8088 & 1.6492 & 25.3145 & 11.3496 \\
\hline & $\mathbf{R}_{\text {adj }}^{2}$ & 0.9824 & 0.0030 & 0.9894 & 0.9758 & 0.9821 & 0.0032 & 0.9909 & 0.9719 & 0.9820 & 0.0036 & 0.9928 & 0.8910 \\
\hline & RMSE & 0.2844 & 0.0246 & 0.3378 & 0.2128 & 0.2866 & 0.0256 & 0.3570 & 0.2024 & 0.2871 & 0.0272 & 0.7099 & 0.1798 \\
\hline \multirow{4}{*}{ 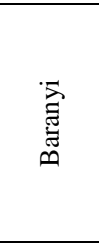 } & $\mu_{\max }$ & 0.1454 & 0.0138 & 0.1862 & 0.1208 & 0.1455 & 0.0115 & 0.1997 & 0.1143 & 0.1456 & 0.0117 & 0.2080 & 0.1146 \\
\hline & $\lambda$ & 17.8898 & 2.1491 & 22.5461 & 12.4060 & 17.8800 & 1.7929 & 23.5385 & 11.6603 & 17.9002 & 1.8335 & 24.6656 & 10.7995 \\
\hline & $\mathrm{R}_{\text {adj }}^{2}$ & 0.9823 & 0.0033 & 0.9907 & 0.9728 & 0.9818 & 0.0033 & 0.9953 & 0.9716 & 0.9819 & 0.0041 & 0.9939 & 0.8681 \\
\hline & RMSE & 0.2846 & 0.0256 & 0.3616 & 0.2083 & 0.2886 & 0.0255 & 0.3629 & 0.2060 & 0.2875 & 0.0286 & 0.7878 & 0.1763 \\
\hline \multirow{2}{*}{ 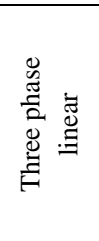 } & $\log _{10} N_{0}$ & 3.9496 & 0.0896 & 4.1481 & 3.7827 & 3.9448 & 0.0879 & 4.1775 & 3.6484 & 3.9474 & 0.0892 & 4.2550 & 3.5989 \\
\hline & RMSE & 0.2923 & 0.0256 & 0.3571 & 0.2247 & 0.2887 & 0.0266 & 0.3681 & 0.1921 & 0.2877 & 0.0264 & 0.3893 & 0.1904 \\
\hline
\end{tabular}

If the mean of the goodness-of-fit indices ( $\mathrm{R}_{\text {adj }}^{2}$ and RMSE) given in Tables 2, S3 and S4 were investigated comparison between the models could be made. Although such a comparison may not be appropriate since MC analysis was based on the perfect fit of each model, it may be useful to differentiate between the number of simulations. For example, the Gompertz model was the best model followed by the Baranyi and three-phase linear models for the data of Lambert et al. (2012) when standard non-linear fitting procedures were applied - see Table 1. This ranking was unchanged after the MC analysis with 100, 1000 and 10000 simulations. On the other hand, although there was a slight difference between the Baranyi model and the three phase linear models, the Baranyi model produced the best fit while the Gompertz model had the worst fit for the second data set (Alavi et al., 1999). MC analysis changed this sequence: the three-phase linear model was the first, the Gompertz model was the second and the Baranyi model was the third for 100 simulations. For 1000 and 10000 simulations threephase linear model was again the best model followed by the Baranyi and the Gompertz models (see Tables S1 and S3).

Comparing coefficient of variation $(\mathrm{CV})(\mathrm{SD} / \mathrm{mean} \times 100)$ of all iterations revealed that similar CVs were obtained for $\log _{10} N_{0}$ and $\log _{10} N_{\max }$ for the models tested (about 1 to 3\%) whereas the Gompertz model had the highest CV (about $10 \%$ ) for $\mu_{\max }$ followed by the Baranyi (about $8 \%$ ) and the three phase linear (about $6 \%$ ) models. For the parameter $\lambda$, the Baranyi model had the CV (about $12 \%$ ) followed by the three phase linear (about 10\%) and the Gompertz (about 9\%) models. This could be better visualized by looking at Fig. 3 where the results of 100 iterations are shown for three models: similar CVs for $\log _{10} N_{0}$ and $\log _{10} N_{\text {max }}$ for all models can be observed in Fig. 3 for the data of Lambert et al. (2012). Furthermore, lower CV values of the parameter $\mu$ for three phase linear model could also be seen; however, interpreting the parameters $\mu_{\max }$ and $\lambda$ was not that easy for the Gompertz and Baranyi models.
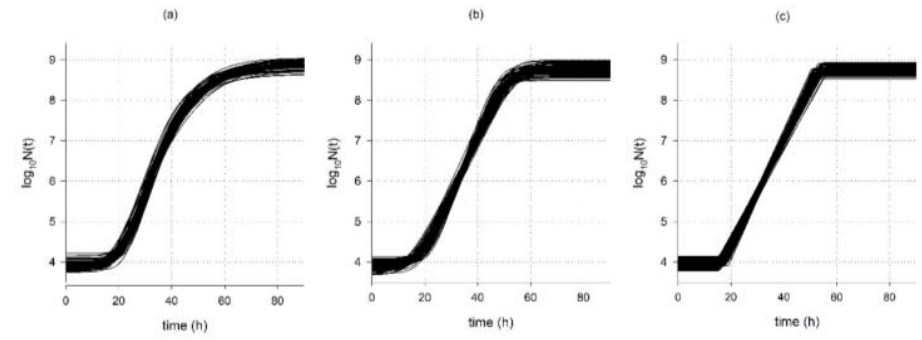

Figure 3 Monte Carlo analysis with 100 simulations for the Gompertz (a); the Baranyi (b) and the three-phase linear (c) models. Original data are from Lambert et al. (2012). 

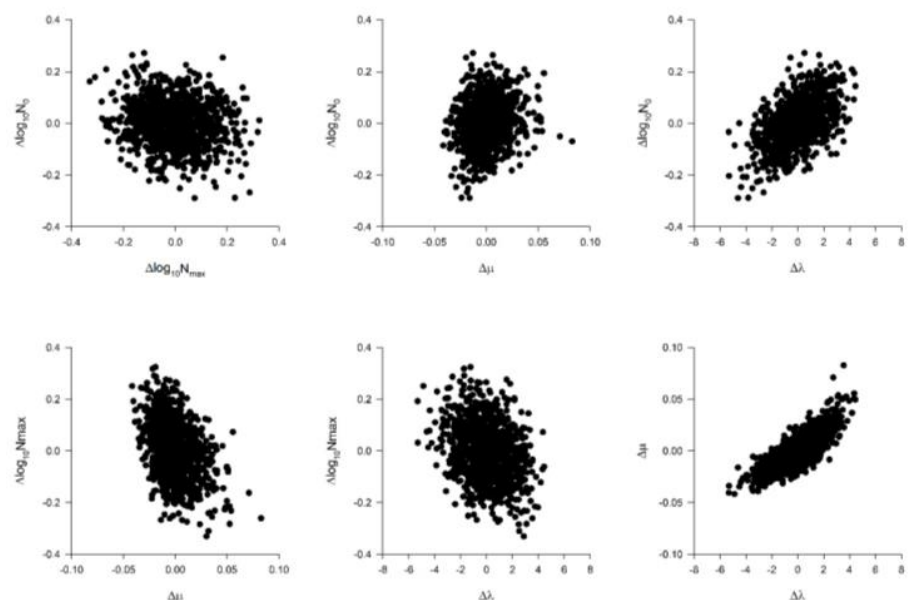

Figure 4 Correlation plots obtained from Monte Carlo analysis with 1000 simulations for the parameters of the Gompertz model. Original data are from Lambert et al. (2012).

MC analysis can also be used to assess the pairwise correlations between parameters (van Boekel, 2009). Figs. 4, 5 and 6 display the results of 1000 iterations of MC analysis for the correlations between the parameters of the Gompertz, the Baranyi and the three phase linear models, respectively. It can be clearly seen that there was a strong correlation between the parameters $\log _{10} N_{0}$ and $\lambda$, and $\mu_{\max }$ and $\lambda$. This was also valid for the other data sets - data not shown. Structural correlations between $\log _{10} N_{0}$ and $\lambda$, and between $\mu_{\max }$ and $\lambda$ for the Gompertz and the Baranyi models were also shown by Baty and DelignetteMuller (2004) by plotting $95 \%$ confidence regions for the $\lambda$ estimates compared to $\log _{10} N_{0}, \log _{10} N_{\max }$ and $\mu_{\max }$. We have shown the same result by using MC analysis with three different data sets including the three-phase linear model. Note that correlations had little or no effect on parameter estimations - see Tables 1, S1 and S2 for parameter values and their corresponding standard errors. High correlation between parameters does not always indicate failure of parameter estimation. Furthermore, the scaled sensitivity coefficients (SSCs) for all 4 parameters for each model (see Dolan and Mishra, 2013 for example) could be used to understand at which part of the experiment there is a correlation between the parameters. SSCs would show that the $\log _{10} N_{0}$ and $\lambda$ were not correlated in the first $1 / 3$ of the experiment, so they can be estimated easily, and the peak of the $\mu_{\max }$ SSC occurred well before the peak of the $\lambda \mathrm{SC}$, that is why these two parameters too can be estimated separately.
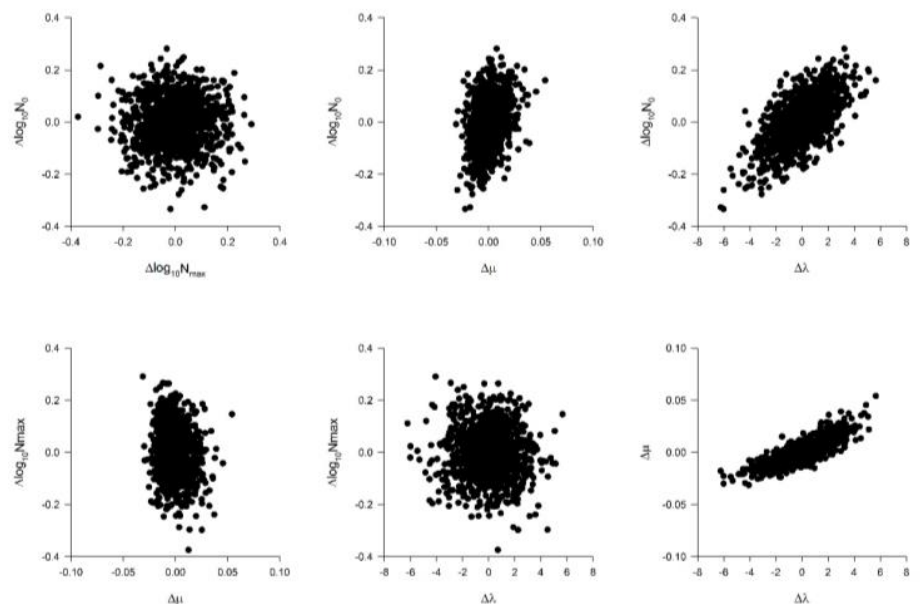

Figure 5 Correlation plots obtained from Monte Carlo analysis with 1000 simulations for the parameters of the Baranyi model. Original data are from Lambert et al. (2012).
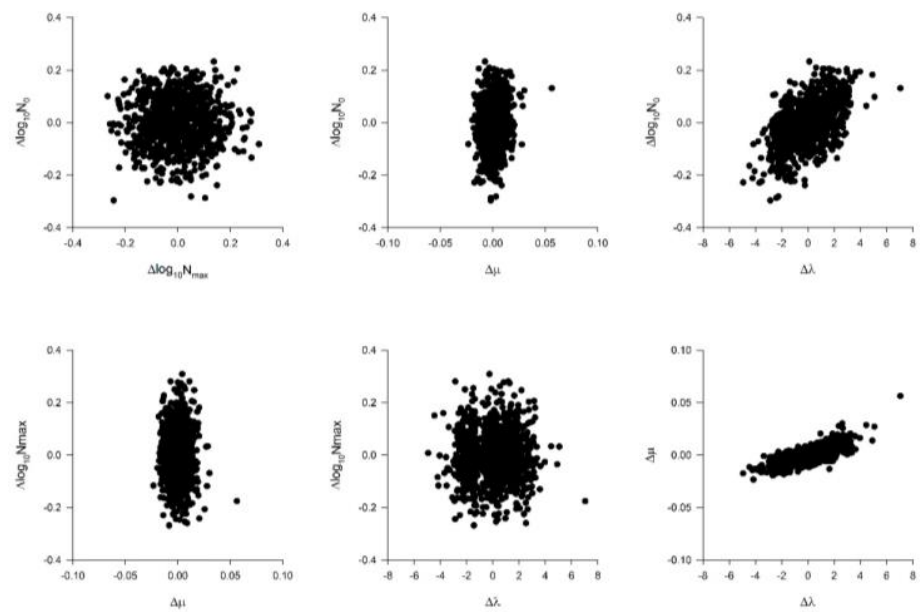

Figure 6 Correlation plots obtained from Monte Carlo analysis with 1000 simulations for the parameters of the three-phase linear model. Original data are from Lambert et al. (2012).
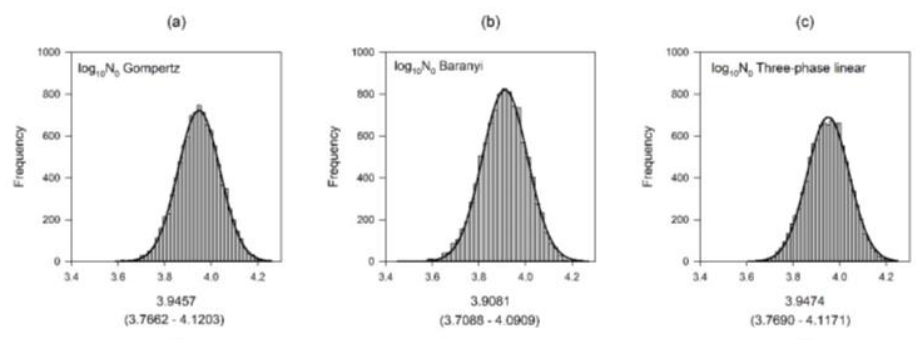

(d)
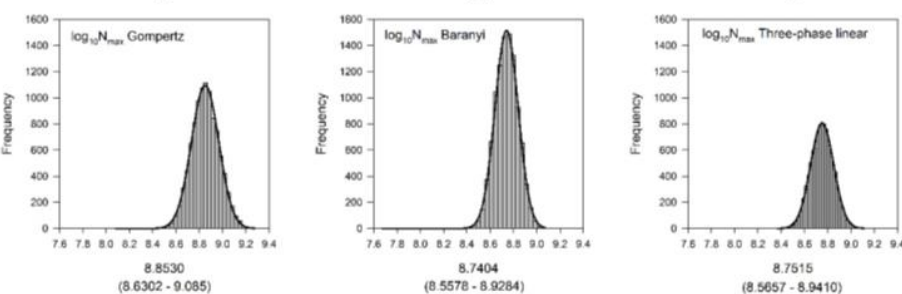

8.7515
$(8.5657-8.9410)$

Figure 7 Histograms of Monte Carlo analysis with 10000 simulations for the parameters $\log _{10} N_{0}$ and $\log _{10} N_{\max }$. Numbers given just under each graph are the mean values and values given in parenthesis are 95\% confidence intervals calculated from the $95 \%$ percentiles. Original data are from Lambert et al. (2012).
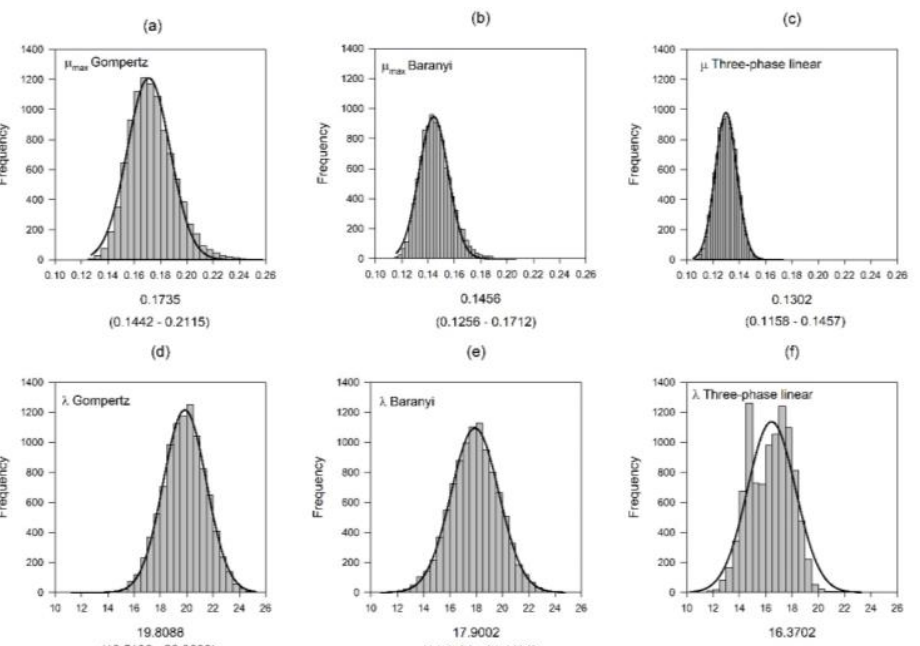

$(134247-191230)$

Figure 8 Histograms of Monte Carlo analysis with 10000 simulations for the parameters $\mu_{\max } \backslash \mu$ and $\lambda$. Numbers given just under each graph are the mean values and values given in parenthesis are $95 \%$ confidence intervals calculated from the 95\% percentiles. Original data are from Lambert et al. (2012). 
Tabulated parameter values given in Table 2 were transformed into histograms for 10000 simulations (Figs. 7 and 8). It was clear from Fig. 7 that distributions for the parameters $\log _{10} N_{0}$ and $\log _{10} N_{\max }$ were normal for all models. Similarly, for the growth rate parameter $\left(\mu_{\max } / \mu\right)$ all models had normal distribution However, histogram for three-phase linear model given in Fig. 8 clearly indicated the deviation from normality for the parameter $\lambda$ which were also true for the other two data sets - see Figs. S5 and S6.

\section{CONCLUSION}

Three most commonly used growth models were fitted to three different data sets and $\mathrm{MC}$ analysis were also performed in the present study. It was observed that $100 \mathrm{MC}$ simulations produced almost identical parameter values with those of 1000 and 10000 simulations. Therefore, it was concluded that using high number of simulations was unnecessary for microbial growth models. All models had similar CV values for the parameters $\log _{10} N_{0}$ and $\log _{10} N_{\max }$. While the Gompertz and the Baranyi models had the highest $\mathrm{CV}$ for the parameters $\mu_{\max }$ and $\lambda$ respectively. $\mathrm{MC}$ analysis also showed that there were strong correlations between the parameters $\log _{10} N_{0}$ and $\lambda$, and $\mu_{\max }$ and $\lambda$. All models' parameters had normal distribution except the parameter $\lambda$ for three-phase linear model

\section{REFERENCES}

Abe, H., Koyama, K., Kawamura, S., \& Koseki, S. (2019). Stochastic modeling of variability in survival behavior of Bacillus simplex spore population during isothermal inactivation at the single cell level using a Monte Carlo simulation. Food Microbiology 82, 436-444. https://doi.org/10.1016/i.fm.2019.03.005.

Alavi, S.H., Puri, V.M., Knabel, S.J., Mohtar, R.H., \& Whiting, R.C. (1999) Development and validation of a dynamic growth model for Listeria monocytogenes in fluid whole milk. Journal of Food Protection 62, 170-176. https://doi.org/10.4315/0362-028x-62.2.170.

Baranyi, J., McClure, P.J., Sutherland, J.P., \& Roberts, T.A. (1993). Modeling bacterial growth responses. Journal of Industrial Microbiology 12, 190-194. https://doi.org/10.1007/BF01584189.

Baranyi, J., \& Roberts, T.A. (1994). A dynamic approach to predicting bacterial growth in food. International Journal of Food Microbiology 23, 277-294. https://doi.org/10.1016/0168-1605(94)90157-0.

Baty, F., \& Delignette-Muller, M.-L. (2004). Estimating the bacterial lag time: which model, which precision? International Journal of Food Microbiology 91, 261-277. https://10.1016/j.ijfoodmicro.2003.07.002.

Buchanan, R.L., Whiting, R.C., \& Damert, W.C. (1997). When is simple good enough: a comparison of the Gompertz, Baranyi, and three-phase linear models for fitting bacterial growth curves. Food Microbiology 14, 313-326 https://doi.org/10.1006/fmic.1997.0125.

Cassin, M.H., Paoli, G.M., \& Lammerding, A.M. (1998). Simulation modeling for microbial risk assessment. Journal of Food Protection 61, 1560-1566. https://doi.org/10.4315/0362-028x-61.11.1560.

Coleman, M.E., \& Marks, H.M. (1999). Qualitative and quantitative risk assessment. Food Control 10, 289-297. https://doi.org/10.1016/S09567135(99)00052-3.

Dalgaard, P. (1995). Modelling of microbial activity and prediction of shelf life for packed fresh fish. International Journal of Food Microbiology 26, 305-317. https://doi.org/10.1016/0168-1605(94)00136-T.

Dolan, K.D. \& Mishra, D.K. (2013). Parameter estimation in food science. The Annual Review of Food Science and Technology 4, 401-422. https://10.1146/annurev-food-022811-101247.

Garre, A., Peñalver-Soto, J.L., Esnoz, A., Iguaz, A., Fernandez, P.S. \& Egea, J.A. (2019). On the use of in-silico simulations to support experimental design: A case study in microbial inactivation of foods. PloS ONE 14, e0220683. https://doi.org/10.1371/journal.pone.0220683.

Gibson, A.M., Bratchell, N., \& Roberts, T.A. (1987). The effect of sodium chloride and temperature on the rate and extent of growth of Clostridium botulinum type A in pasteurized pork slurry. Journal of Applied Bacteriology 62, 479-490. https://doi.org/10.1111/j.1365-2672.1987.tb02680.x.

Gompertz, B. (1825). On the nature of the function expressive of the law of human mortality, and on a new mode of determining the value of life contingencies. Philosophical Transactions of the Royal Society of London, 513 583.

Gwak, E., Oh, M.-H., Park, B.-Y., Lee, H., Lee, S., Ha, J., Lee, J., Kim, S., Choi, K.-H., \& Yoon, Y. (2015). Probabilistic models to predict Listeria monocytogenes growth at low concentrations of $\mathrm{NaNO}_{2}$ and $\mathrm{NaCl}$ in frankfurters Korean Journal for Food Science of Animal Resources 35, 815-823. http://dx.doi.org/10.5851/kosfa.2015.35.6.815.

Heldman, D.R., \& Newsome, R.L. (2003). Kinetic models for microbial survival during processing. Food Technology 57, 40-46.
Lebert, I., \& Lebert A. (2006). Quantitative prediction of microbial behaviour during food processing using an integrated modelling approach: a review. International Journal of Refrigeration 29, 968-984. https://doi.org/10.1016/j.ijrefrig.2006.04.008.

Jarvis, B. (1989). Statistical Aspects of the Microbiological Analysis of Foods. Progress in Industrial Microbiology, vol. 21. Elsevier, Amsterdam.

Jaloustre, S., Cornu, M., Morelli, E., Noël, V., \& Delignette-Muller, M.L. (2011). Bayesian modeling of Clostridium perfringens growth in beef-in-sauce products. Food Microbiology 28, 311-320. https://doi.org/10.1016/j.fm.2010.04.002.

Koyama, K., Abe, H., Kawamura, S., \& Koseki, S. (2019). Stochastic simulation for death probability of bacterial population considering variability in individual cell inactivation time and initial number of cells. International Journal of Food Microbiology 290, 125-131. https://doi.org/10.1016/j.ijfoodmicro.2018.10.009. Lambert, R.J.W., Mytilinaios, I., Maitland, L., \& Brown, A.M. (2012). Monte Carlo simulation of parameter confidence intervals for non-linear regression analysis of biological data using Microsoft Excel. Computer Methods Programs in Biomedicine 107, 155-163. https://doi.org/10.1016/j.cmpb.2011.05.009.

$\begin{array}{lcc}\text { Lovy, } & \text { D., } & 2002 . \\ \text { http://www.unige.ch/sciences/chifi/cpb/windig.html. }\end{array}$

WinDIG

Manthou, E., Tarlak, F., Linaou, A., Ozdemir, M., Zervakis, G.I., Panagou, E.Z., \& Nychas, G-J.E. (2019). Prediction of indigenous Pseudomonas spp. growth on oyster mushrooms (Pleurotus ostreatus) as a function of storage temperature. LWT - Food Science and Technology 111, 506-512. https://doi.org/10.1016/j.lwt.2019.05.062.

McKellar, R.C. (1997). A heterogeneous population model for the analysis of bacterial growth kinetics. International Journal of Food Microbiology 36, 179 186. https://doi.org/10.1016/S0168-1605(97)01266-X.

McKellar, R.C., \& Knight, K. (2000). A combined discrete-continuous model describing the lag phase of Listeria monocytogenes. International Journal of Food Microbiology 54, 171-180. https://doi.org/10.1016/S0168-1605(99)002044.

McKellar, R.C., \& Lu, X. (2004). Primary models. In: R.C. McKellar, X., Lu (Eds.) Modeling Microbial Responses in Food CRC Press, Boca Ratón, FL.

Membré, J.M., Ross, T., \& McMeekin, T. (1999). Behaviour of Listeria monocytogenes under combined chilling processes. Letters in Applied Microbiology 28, 216-220. https://doi.org/10.1046/j.1365-2672.1999.00499.x.

Mossel, D.A.A., Corry, J.E.L., Struijk, C.B., \& Baird, R.M. (1995). Essentials of the microbiology of foods: a textbook for advanced studies. John Wiley \& Sons, Chichester.

Nauta, M.J. (2000). Separation of uncertainty and variability in quantitative microbial risk assessment models. International Journal of Food Microbiology 57, 9-18. https://doi.org/10.1016/S0168-1605(00)00225-7.

Nicolaï, B.M., \& Van Impe, J.F. (1996). Predictive food microbiology: a probabilistic approach. Mathematics and Computers in Simulation 42, 287-292. https://doi.org/10.1016/0378-4754(95)00129-8.

Peleg, M., \& Corradini, M.G. (2011). Microbial growth curves: what the models tell us and what they cannot. Critical Reviews in Food Science Nutrition 51, 917 945. http://dx.doi.org/10.1080/10408398.2011.570463.

Poschet, F., Geeraerd, A.H., Scheerlinck, N., Nicolai, B.M., \& Van Impe, J.F. (2003). Monte Carlo analysis as a tool to incorporate variation on experimental data in predictive microbiology. Food Microbiology 20, 285-295. https://doi.org/10.1016/S0740-0020(02)00156-9.

Poschet, F., Bernaerts, K., Geeraerd, A.H., Scheerlinck, N., Nicolai, B., \& Van Impe, J.F. (2004). Sensitivity analysis of microbial growth parameter distributions with respect to data quality and quantity by using Monte Carlo analysis. Mathematics Computers in Simulation 65, 231-243. https://doi.org/10.1016/j.matcom.2003.12.002.

Poschet, F., Vereecken, K.M., Geeraerd, A.H., Nicolai, B., \& Van Impe, J.F (2005). Analysis of a novel class of predictive microbial growth models and application to coculture growth. International Journal of Food Microbiology 100, 107-124. https://doi.org/10.1016/j.ijfoodmicro.2004.10.008.

Ratkowsky, D.A. (2004). Model fitting and uncertainty. In: R.C. McKellar, X., Lu (Eds.) Modeling microbial responses in food. CRC Press Boca Raton FL, pp. 151-196.

van Boekel, M.A.J.S. (2009). Kinetic modeling of reactions in foods. CRC press Boca Raton FL.

van Boekel, M.A.J.S. (2020). On the pros and cons of Bayesian kinetic modeling in food science. Trends in Food Science and Technology 99, 181-193. https://doi.org/10.1016/j.tifs.2020.02.027.

Whiting, R., \& Cygnarowicz-Provost, M. (1992). A quantitative model for bacterial growth and decline. Food Microbiology 9, 269-277. https://doi.org/10.1016/0740-0020(92)80036-4.

Winsor, C.P. (1932). The Gompertz curve as a growth curve. Proceedings of the National Academy of Sciences of the United States of America 18, 1-8.

Zwietering, M.H., Jongenburger, I., Rombouts, F.M., \& Van't Riet, K.J.A.E.M (1990). Modeling of the bacterial growth curve. Applied Environmental Microbiology 56, 1875-1881. 